\title{
Comparação da duração da carreira de filtração entre filtro lento com limpeza convencional e retrolavável
}

Comparison on the duration of career between slow sand filter with conventional cleaning and backwashed slow sand filter

\author{
D. C. G. S. Michelan ${ }^{1 *}$; M. L. Sens; R. L. Dalsasso ${ }^{2}$ \\ ${ }^{I}$ Departamento de Engenharia Civil, Universidade Federal de Sergipe, 49100-000, São Cristóvão-SE, Brasil \\ ${ }^{2}$ Departamento de Engenharia Ambiental, Universidade Federal de Santa Catarina, 88040-900, Florianópolis-SC, \\ Brasil \\ *denise_gois@yahoo.com.br \\ (Recebido em 10 de junho de 2015; aceito em 29 de outubro de 2015)
}

\begin{abstract}
A filtração lenta é uma técnica de tratamento de água para consumo humano bastante antiga, datada de 1804. Apesar de ser antiga, continua tendo significativa utilidade. O seu processo de tratamento se baseia na purificação de água, por meio do uso da areia como meio filtrante, para reter as impurezas. A proposta aqui apresentada está pautada na comparação da filtração lenta, entre formas de limpeza do meio filtrante: convencional ou por retrolavagem. A forma convencional ocorre por raspagem da superfície do meio filtrante, enquanto que por retrolavagem, se baseia no contra fluxo de água filtrada para expandir o meio filtrante, com consequente arraste das impurezas que ficaram retidas no meio filtrante e acima do mesmo, de modo a separar o meio filtrante das impurezas. A comparação ocorreu em função da duração da carreira de filtração dos filtros. Apesar do filtro lento com limpeza retrolavável ser considerado mais rápido durante a limpeza do meio filtrante, a duração média das carreiras de filtração foi de apenas 17 dias, isso pode ser indicador de que o perfil da camada filtrante continuou enriquecido de flora microbiana, necessário para a carreira de filtração seguinte, enquanto que o filtro lento com limpeza convencional teve duração de limpeza de aproximadamente, 50 vezes mais demorado do que o filtro lento com limpeza retrolavável. A duração média das carreiras de filtração, do filtro lento com limpeza convencional foi de 22 dias, sendo assim mais duradouras.

Palavras-chave: filtração lenta, limpeza convencional, limpeza retrolavável.
\end{abstract}

Slow sand filter is a water treatment technique for human consumption very old, dated 1804. Despite being old, it continues to have significant utility. The treatment process is based on water purification through the use of sand as filter environment to retain the impurities. The proposal presented is guided in comparing the slow sand filter, between forms of cleaning the filter medium: conventional or backwashing. The conventional way is by scraping the surface of the filter medium, whereas by backwash, is based on the against flow of the filtered water to expand filter medium, with consequent dragging of the impurities that were retained in the filter medium and over the same, so separating the filter medium of impurities. The comparison was due to the duration of the filters filtration career. Despite filter slow with backwash to be considered faster during the clean of the filter medium, the average duration of the filtration career was only 17 days. This may be an indicator that the profile of the filter layer continued enriched with microbial flora, it is required for the following filtration career, while the filter slow conventional cleaning had duration approximate 50 times slower than the filter slow backwashed. The average duration of filtration careers, of the filter slow conventional cleaning was 22 days, so most enduring.

Keywords: slow filtration, conventional cleaning, backwashed.

\section{INTRODUÇÃO}

Em geral, os tratamentos convencionais de água abrangem a coagulação, floculação, decantação, filtração, desinfecção e fluoretação e são encontrados nas Estações de Tratamento de Água (ETA's) nas grandes cidades. Entretanto muitas vezes as técnicas apresentadas para proporcionar um tratamento satisfatório são inviáveis economicamente para as cidades pequenas. Torna-se, desta forma, crescente a necessidade de se buscar alternativas de tratamento de água de modo simples e sem incrementos tecnológicos, que dificultam a manutenção do sistema de tratamento. 
Uma alternativa possível é a filtração lenta que é considerada processo de purificação de água de forma eficiente, simples, natural e não poluente. Esse processo associa mecanismos de aderência e transporte que ocorrem no meio filtrante, somado à biodegradação que se sucede na película, denominado camada microbiana ou biofilme, que se forma na superfície do meio filtrante. Essa película é composta de matéria orgânica, partículas inertes e por espécies de microrganismos, que por ações físicas, químicas e bioquímicas, utilizam a matéria orgânica misturada à água bruta, como substrato para seu desenvolvimento, biodegradando a matéria orgânica [1]. Além de microrganismos, a exemplo, quando a água bruta apresenta concentração de ferro, manganês e/ou alumínio em estado solúvel, pode ocorrer a precipitação destes metais, que ficarão retidos na parte da película [2].

Nesse contexto, a proposta de estudo, pautada na filtração lenta, baseou-se em dois sistemas de filtração, no qual um deles com limpeza do filtro de forma convencional, por meio de raspagem do meio filtrante e o outro, por meio de retorno de parte da água filtrada, por contrafluxo, para expandir o meio filtrante e consequentemente, arraste das impurezas de menor densidade que o meio filtrante. O primeiro citado é denominado de filtro lento com limpeza convencional (FLC) e o segundo, filtro lento com limpeza retrolavável (FLR).

O FLC é considerado eficiente em termos de custo de implantação e manutenção, porque dispensa equipamentos especiais e mão de obra especializada. Como o FLR difere apenas no processo de limpeza, este também é considerado eficiente em termos de custo de implantação e manutenção, porém será um pouco mais custoso que o convencional porque é necessária a implantação do reservatório de água de lavagem. Entretanto se busca a informação se o desempenho em termo de durabilidade no funcionamento na carreira de filtração será eficiente com a limpeza retrolavável.

A limpeza retrolavável, costumeiramente utilizada na filtração rápida, é usada como proposta na filtração lenta, de modo a buscar facilidade na limpeza e redução do tempo em que o filtro lento permanece sem produzir água tratada, por estar em período de limpeza. Assim o FLR vem mostrar que é tão eficiente quanto o FLC, além de praticidade em termos de limpeza.

Com base nessas informações o presente estudo traz a comparação na eficiência em termos de duração da carreira de filtração, entre a filtração lenta com limpeza retrolavável e convencional.

\section{MATERIAL E MÉTODOS}

Ambos os filtros (FLR e FLC) receberam água de igual destino, qualidade e vazão. O que os diferencia é a forma de limpeza. O FLC foi limpo por meio de raspagem dos centímetros iniciais do meio filtrante. O FLR recebeu água, já filtrada, reservada em reservatório de água de lavagem que retornou ao filtro com movimento ascendente, de modo a limpá-lo.

Em análises preliminares de amostras de água bruta, percebeu-se que essas águas não continham algas e sim ferro total em excesso, o que indicou a escolha de filtros cobertos. Esta água foi bombeada, de modo que os filtros funcionaram em paralelo. Foram construídos em alvenaria armada com tijolos maciços, rebocados com argamassa 1:2:1 (cimento:areia:água), laje de fundo em concreto armado de $15 \mathrm{~cm}$, com traço 1:3:2 (cimento: areia média: brita $\mathrm{n}^{\circ} 2$ ) e acrescido dosagem de impermeabilizante. A fundação da laje teve profundidade de $2,5 \mathrm{~m}$ a partir do nível do terreno e foi confeccionada em toras de madeira de $30 \mathrm{~cm}$. O meio filtrante dos filtros foi composto por camada de areia de $40 \mathrm{~cm}$, com diâmetro efetivo de $0,3 \mathrm{~mm}$, coeficiente de desuniformidade $<1,5$ [3] e camada suporte de $20 \mathrm{~cm}$ ( $\phi$ de 1,4 a 4,5 $\mathrm{mm}$ ).

Os filtros tiveram dimensões internas de $0,80 \times 0,80 \mathrm{~m}$. Operaram em regime constante e carga hidráulica variável até alcançar a perda de carga final de 1,00 m. Di Bernardo e Sabogal Paz (2008) [2] recomendam que a perda de carga final esteja entre 1,0 e 2,0 m, que em geral, corresponde à duração de carreira com tempo acima de 30 dias. A perda de carga foi medida em piezômetros, no qual o progresso da perda de carga foi acompanhado até se alcançar 1,00 m. Os piezômetros foram montados por meio de mangueiras plásticas e indicação métrica (ambas localizadas na parede externa dos filtros), de modo a facilitar a leitura (Figura 1). 


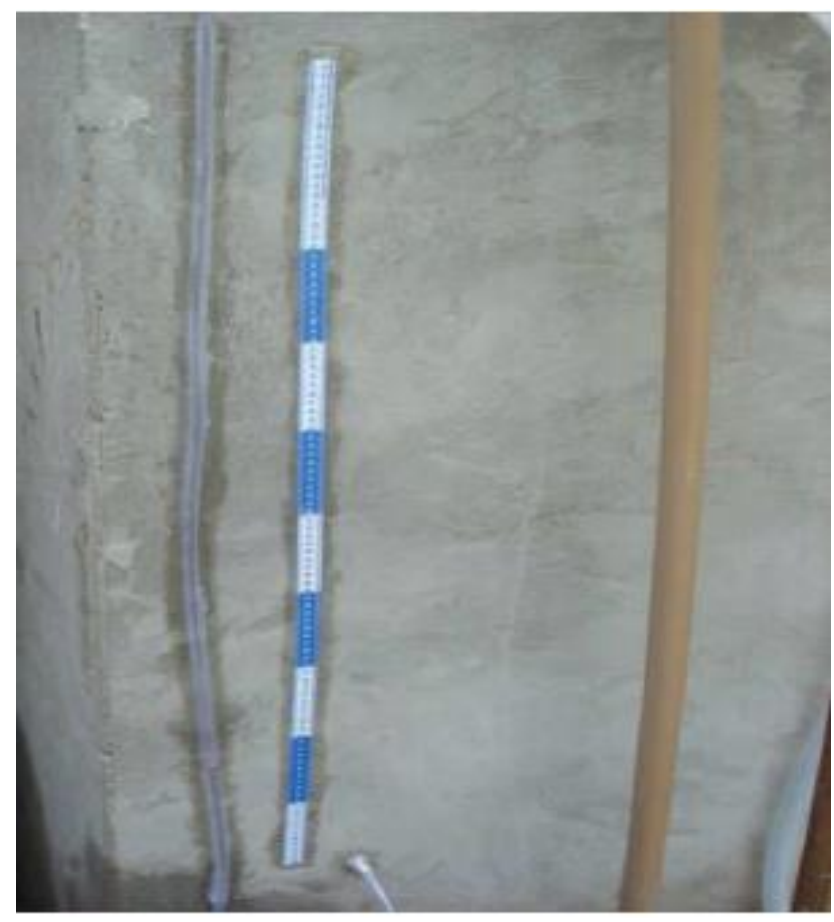

Figura 1: Foto do piezômetro construído com mangueira com acompanhamento de carga por meio de fita métrica.

Di Bernardo e Sabogal Paz (2008) [2] recomendam que a taxa de filtração esteja compreendida entre 2 e $3 \mathrm{~m}^{3} / \mathrm{m}^{2}$.d, por isso a escolhida foi de $3 \mathrm{~m}^{3} / \mathrm{m}^{2} . \mathrm{d}$ com vistas a possibilitar uma maior produção de água tratada, obtendo-se vazão de $1920 \mathrm{~L} / \mathrm{d}$ ou $80 \mathrm{~L} / \mathrm{h}$.

A limpeza do FLC foi realizada cada vez que o nível de água no filtro alcançava a perda de carga máxima. Quando esta situação acontecia, era aberto um registro de fundo, para facilitar a saída da água. Segundo Di Bernardo e Sabogal Paz (2008) [2], esta limpeza deve ocorrer por raspagem entre 1 e $5 \mathrm{~cm}$ da camada de areia. Na prática, seguiram-se as recomendações dos autores, raspando-se $5 \mathrm{~cm}$. Entretanto, o volume de material retirado do FLC foi muito maior, porque, na superfície da camada filtrante, formou-se uma espessa camada gelatinosa de ferro (Figura 2) misturado à camada microbiana, com espessura média de $8 \mathrm{~cm}$.

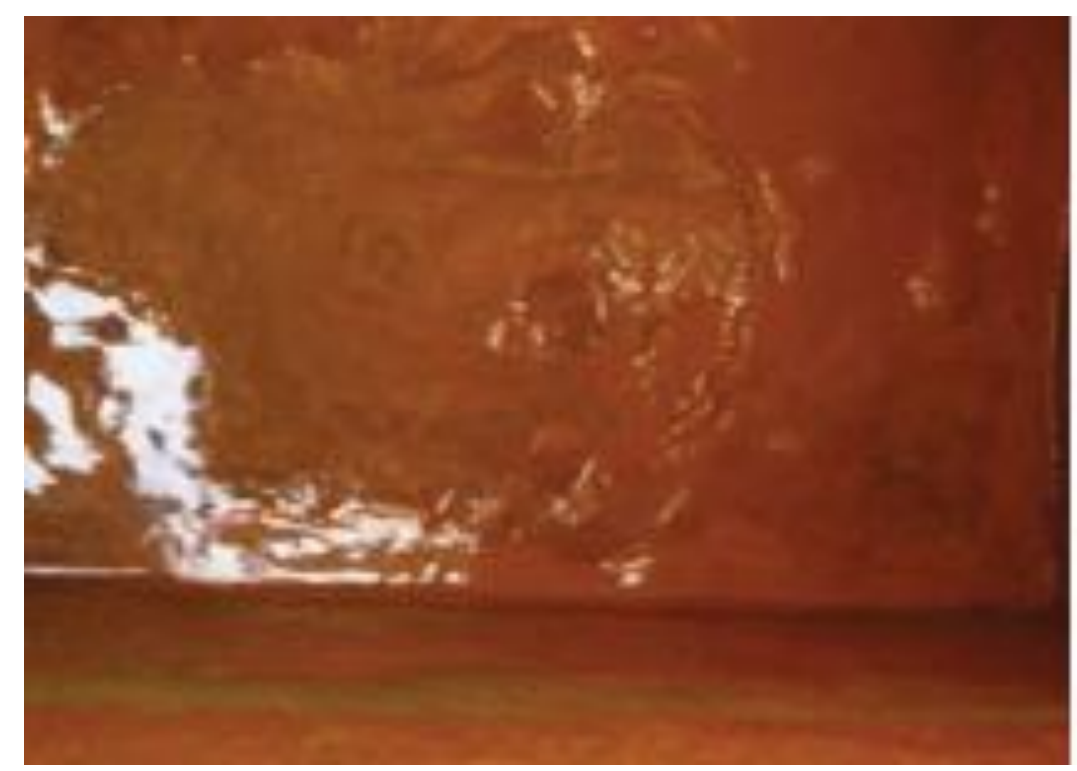

Figura 2: Foto da camada gelatinosa acima do meio filtrante, dentro do filtro lento. 
A areia foi retirada do filtro, lavada com água filtrada e reposta ao filtro, antes dele ser colocado novamente em operação, para não comprometer a qualidade da água filtrada por estar com espessura de areia reduzida e também para sempre ter a mesma espessura que o FLR. A retirada da camada gelatinosa+camada microbiana e raspagem da areia ocorreu em tempo médio de 1 hora. A lavagem era mais demorada, porque a camada raspada de areia, continha flocos de ferro gelatinoso, o que compreendeu tempo médio de 2 horas. A reposição dessa areia, de forma nivelada, durou apenas $20 \mathrm{~min}$. Ou seja, ao todo, a etapa da limpeza do FLC durou, em média, 3 horas e $20 \mathrm{~min}$.

Segundo Solsona (1993) [4], a duração da limpeza realizada manualmente varia entre 4 e 8 horas e segundo Logsdon et al. (2002) [5] a área de $100 \mathrm{~m}^{2}$ precisa de pelo menos 5 horas.

A limpeza do FLR também foi realizada com perda de carga máxima. Nessa situação, não era aberto o registro de fundo e sim, o registro de saída da água localizado logo acima do meio filtrante. Nesse filtro foi calculado o volume do reservatório de água de lavagem, porque esse volume de água tinha a função de limpar o meio filtrante. Esta limpeza teve duração de apenas 4 minutos. Segundo Emmendoerfer (2006) [6], à medida que a água presente no filtro saía dele, por diferença de carga hidráulica e por contra fluxo (sem uso de bomba), a água de lavagem retornava ao filtro, expandindo a areia em torno de $40 \%$, velocidade da água de $0,35 \mathrm{~m} / \mathrm{min}$ no contra fluxo, proveniente da água de lavagem e vazão de $224 \mathrm{~L} / \mathrm{min}$.

\section{RESULTADOS E DISCUSSÃO}

A partir do momento em que a perda de carga nos sistemas FLR e FLC alcançou 1,00 m, era considerado final da carreira de filtração. Como foram coletadas amostras depois do início e no final da carreira, os valores dos parâmetros não apresentaram diferenças significativas, o que indicou que com 1,0 m de perda de carga, não aconteceu o transpasse de impureza (ou deterioração da qualidade da água), apesar da camada de areia ser de apenas $40 \mathrm{~cm}$.

$\mathrm{Na}$ Tabela 1, é apresentado o tempo de duração das carreiras de filtração para cada sistema, na qual, observa-se que inicialmente as carreiras de filtração foram pouco duradouras, com duração de até 10 dias para o FLR e com 13 dias para o de FLC. A primeira carreira de filtração ocorreu após 4 meses de manutenção inicial e mais um mês de aclimatação. Acredita-se que, apesar de se ter esperado o tempo de acomodação da camada de areia de cada filtro e também o crescimento da flora microbiana na mesma, estas carreiras ainda não estavam aclimatadas, ou seja, ainda não havia formação de microrganismos suficiente para o tratamento de água.

Tabela 1: Duração das carreiras de filtração nos filtros lentos.

\begin{tabular}{ccc}
\hline Carreiras de filtração & FLC duração (dias) & FLR duração (dias) \\
\hline $1^{\circ}$ & 12 & 8 \\
$2^{\circ}$ & 13 & 10 \\
$3^{\circ}$ & 21 & 20 \\
$4^{\circ}$ & 28 & 20 \\
$5^{\circ}$ & 26 & 21 \\
$6^{\circ}$ & 27 & 20 \\
$7^{\circ}$ & 24 & 20 \\
$8^{\circ}$ & 23 & 23 \\
$9^{\circ}$ & 24 & 22 \\
$10^{\circ}$ & 23 & 23 \\
$11^{\circ}$ & 27 & 23 \\
$12^{\circ}$ & 16 & 20 \\
$13^{\circ}$ & 27 & 16 \\
$14^{\circ}$ & - & 16 \\
\hline
\end{tabular}


Geralmente os filtros lentos têm duração média de carreira de filtração de 30 dias. Em nenhum período de monitoramento, alcançou este tempo. Acredita-se que, como a concentração de ferro total na água bruta apresentou valores significativos ao longo do período em estudo, este tenha interferido na duração as carreiras de filtração. Nas Figuras 3 e 4, são apresentados os comportamentos das carreiras de filtração dos sistemas, com o correspondente progresso da perda de carga.

O acompanhamento do progresso da perda de carga foi realizado diariamente ou, no máximo, a cada dois dias. Enquanto o FLC teve em média, duração de carreiras de filtração de 22 dias, o FLR teve tempo médio de duração das carreiras de apenas 17 dias. Como ambos os sistemas receberam a mesma água em qualidade e vazão, o FLC teve uma quantidade maior de carreiras mais duradouras, do que o FLR.

A duração de carreiras de filtração pode estar associada à melhor limpeza do meio filtrante do FLC do que no FLR, devido ao ferro depositado acima da camada filtrante.

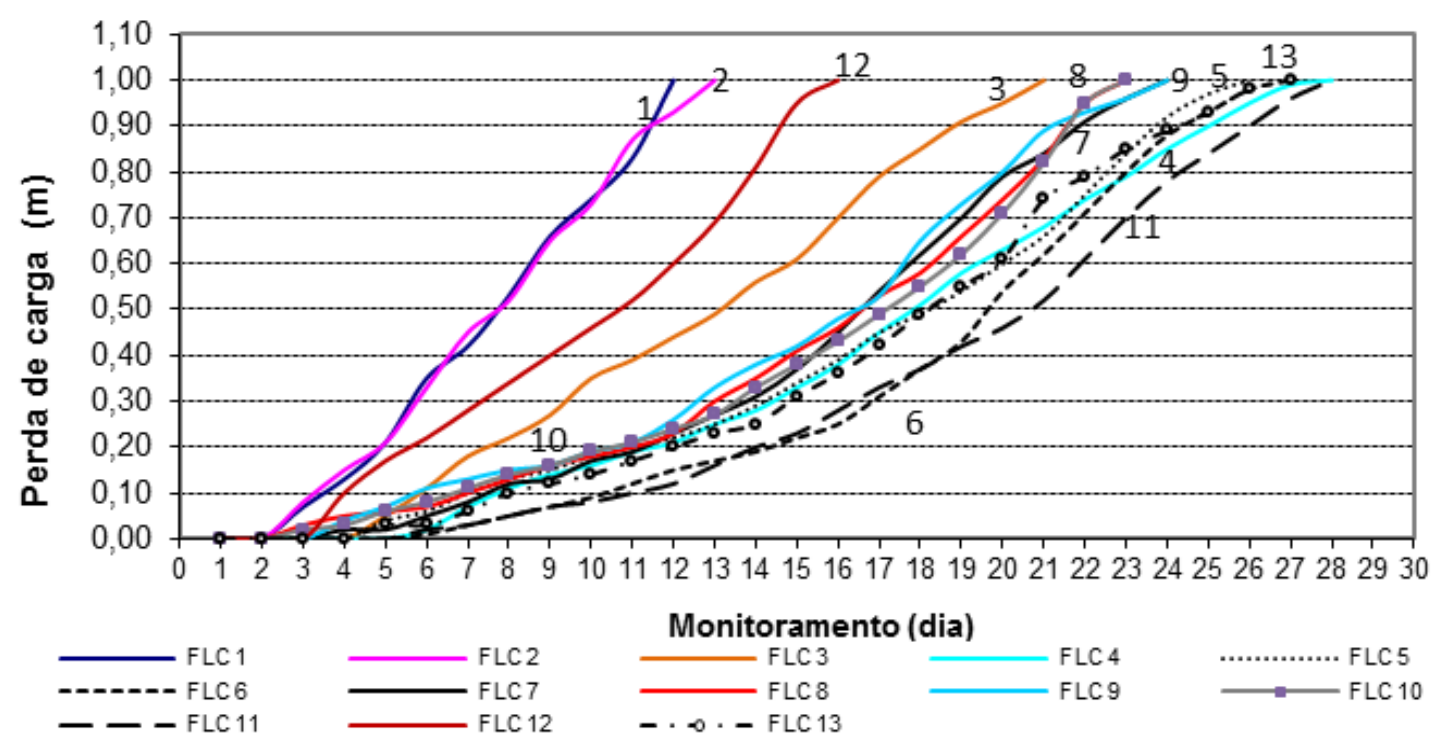

Figura 3: Monitoramento da perda de carga nas carreiras de filtração do FLC.

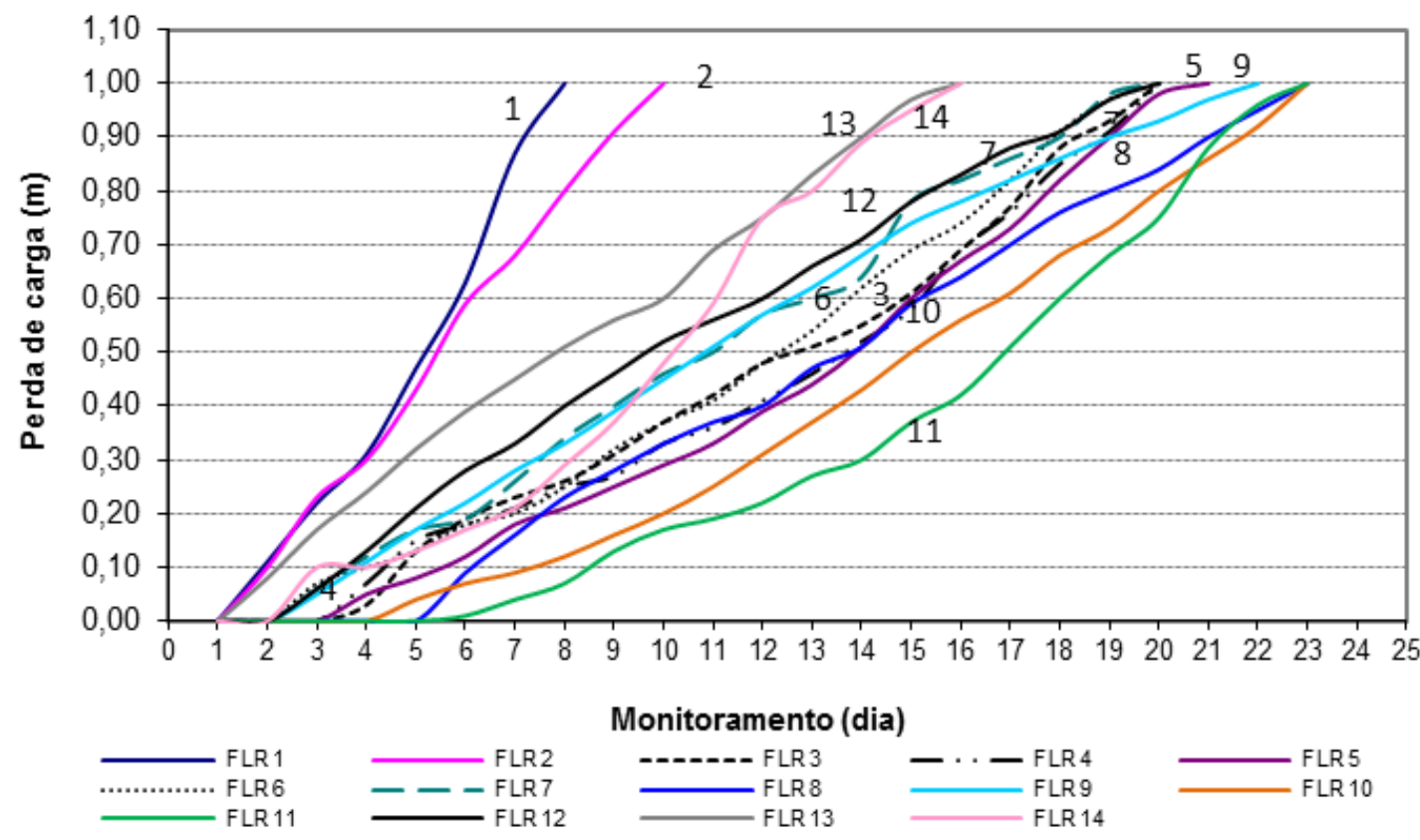

Figura 4: Monitoramento da perda de carga nas carreiras de filtração do FLR. 


\section{CONCLUSÃO}

Em termos de praticidade de lavagem, o FLR consumiu 50 vezes menos tempo para realizar que o FLC. Com apenas 4 minutos, foi realizada a limpeza do meio filtrante do FLR, enquanto que a limpeza foi realizada no FLC em 3 horas e 20 minutos. Por meio apenas da abertura de um registro, realiza-se a limpeza do meio filtrante do filtro retrolavável, enquanto que no convencional é necessário esgotar o filtro, raspar a areia, lavá-la e em seguida retorná-la para o filtro, para enfim colocar em funcionamento.

O sistema de lavagem do FLR foi considerado rápido na limpeza do meio filtrante. Entretanto, pelo fato da duração média das carreiras de filtração ter sido de apenas 17 dias, isso pode ser indicador de que o perfil da camada filtrante continuou enriquecido de flora microbiana, necessário para a carreira de filtração seguinte, enquanto que a duração média da carreira de filtração do filtro lento com limpeza convencional foi de 22 dias.

\section{AGRADECIMENTOS}

Agradecimento à Universidade Federal de Santa Catarina (UFSC) pelo desenvolvimento do doutorado, como discente regular, e ao $\mathrm{CNPq}$, pela bolsa concedida durante a realização do doutorado do primeiro autor, no qual este trabalho é fruto parcial da tese.

\section{REFERÊNCIAS BIBLIOGRÁFICAS}

1. Rocha, VC, Heller, L, Costa, BMP, Libanio, M. Avaliação da influência do sentido do escoamento na filtração lenta na remoção de cor em água de abastecimento. In: Simpósio Luso-Brasileiro de Engenharia Sanitária e Ambiental. IX Simpósio; 2000, abril 9-14; Porto Seguro. CD-ROM.

2. Di Bernardo, L.; Sabogal Paz, LP. Seleção de Tecnologias de Tratamento de Água. São Carlos: Editora LDIBE LTDA, v1, 878p e v2; 2008. 682p

3. Cleasby, JL. Filtração. Water quality and treatment, F.W. Pontius. New York: McGraw Hill; 1990. 870p.

4. Solsona, F. Guide Techinal. Dynamic Filtration. Pretoria, South Africa; 1993. 75p.

5. Logsdon, GS, Kohne, R, Solomon, A, La BONDE, S. Slow sand filtration for small water systems. Journal Environ. Eng. Science. 2002, (1):339-348.

6. Emmendoerfer, ML. Filtração lenta com retrolavagem para propriedades rurais de uso familiar [Trabalho de Conclusão de Curso]. Florianópolis (Santa Catarina). Universidade Federal de Santa Catarina: Departamento de Engenharia Sanitária e Ambiental; 2006. 48p. 